\title{
Multimodality locoregional treatment strategies for bridging HCC patients before liver transplantation
}

\author{
Georg P. Györi · D. Moritz Felsenreich · Gerd R. Silberhumer · Thomas Soliman · Gabriela A. Berlakovich
}

Received: 21 March 2017 / Accepted: 24 July 2017 / Published online: 4 September 2017

(C) The Author(s) 2017. This article is an open access publication.

\begin{abstract}
Summary
Background It is current practice that patients with hepatocellular carcinoma (HCC) listed for liver transplantation should receive locoregional treatment if the suspected waiting time for transplantation is longer than 6 months, even in the absence of prospective randomized data. Aim of this study was the comparison of single versus multimodality locoregional treatment strategies on outcomes after liver transplantation.

Methods This is a retrospective analysis of 150 HCC patients listed for liver transplantation at our center between 2004 and 2011. Outcomes were analyzed according to modified Response Evaluation Criteria in Solid Tumors (mRECIST) in relation to intention-totreat and overall survival after liver transplantation. Results Overall, 92 patients (63\%) were transplanted in this cohort. The intention-to-treat 1-, 3-, 5-year waiting list survival was 80,59 , and $50 \%$ respectively. In RFA-(radiofrequency ablative) and TACE-(transarterial chemoembolisation)-based regimens, rates of transplanted patients were comparable (69 vs. $58 \%$, $p=\mathrm{ns})$. No difference was seen in overall survival after liver transplantation when comparing TACE- and RFA-based regimens. Patients receiving multimodality locoregional therapy had lower overall survival after transplantation $(p=0.05)$

Conclusion TACE- and RFA-based regimens showed equal outcomes in terms of transplantation rate, tumor response, and post-transplant survival. Patients
\end{abstract}

G. P. Györi, MD $(\bowtie)$ • D. M. Felsenreich · G. R. Silberhumer · T. Soliman · G. A. Berlakovich

Department of Surgery, Division of Transplantation, Medical University of Vienna, Währinger Gürtel 18-20, 1090 Vienna, Austria

georg.gyoeri@meduniwien.ac.at in need of more than one treatment modality might identify a cohort with poorer post-transplant survival. Points of novelty Direct comparison of TACE and RFA in a multimodality setting, analysis according to mRECIST.

Keywords Hepatocellular carcinoma - Liver transplantation - Ablation techniques - Bridging - Downstaging

\section{Introduction}

Orthotropic liver transplantation (OLT) is the standard curative treatment for selected patients with hepatocellular carcinoma (HCC), considering that the majority present with concomitant cirrhosis at the time of diagnosis and are not amenable to resection [1].

Restrictions in tumor size and number of nodules have been implemented in order to establish good post-transplantation outcomes [2, 3]. Over the past decade, many centers were able to extend the selection criteria while maintaining comparable outcomes $[4,5]$. Even though HCC patients within certain selection criteria are prioritized in terms of allocation throughout the world, tumor progression and waiting list dropouts represent significant problems in the management of HCC patients [6, 7].

Locoregional therapies (LRT) deliver toxic thermal/ chemical/radioactive doses to tumors with minimal toxicity to normal tissue. Transarterial chemoembolization (TACE) and yttrium-90 radioembolization are LRTs that have demonstrated a palliative role in HCC patients [8]. Their role in downstaging transplant patients and bridging patients to transplantation is currently under debate, and data are scarce. Locoregional therapies have been successfully used to prevent tumor progression on the waiting list [9]. 
For HCC lesions under $3 \mathrm{~cm}$ (single or up to three), radiofrequency ablation (RFA) is the preferred LRT; for multinodular tumors (more than three lesions) or single lesions more than $3 \mathrm{~cm}$, TACE is the preferred LRT [10].

Additionally, patients primarily beyond listing criteria were added to the waiting lists after tumor reduction via LRTs [11-13].

Aim of this study was the comparison of locoregional treatment strategies on both waiting list and transplant survival in a large patient series.

\section{Patients and methods}

All HCC patients listed for liver transplantation in our center between January 2004 and December 2011 were included in this retrospective analysis.

Collected data included standard demographic data (age, gender) as well as preoperative staging, Milan criteria status, date of listing, waiting time, modality of locoregional therapy, number of treatments, and treatment-associated morbidity including severe adverse events (SAE) within 4 weeks.

An intention-to-treat (ITT) analysis was performed for all patients. In addition, patients were grouped according to their main pre-transplant ablative regimes used for bridging to transplantation: (i) transarterial chemoembolization, (ii) ablative strategies such as radiofrequency ablation in combination with/without percutaneous alcohol instillation (PEI), or (iii) no bridging. For patients receiving more than one LRT modality, subgroup analysis was performed (mmLRT).

Routine CT scans for tumor evaluation were performed at the time of listing, as well as every 3 months during the waiting time.

Histological examination of all explanted livers was performed in all transplanted patients.

Response to LRT was grouped as described in the modified Response Evaluation Criteria in Solid Tumors (mRECIST): complete response: CR (tumor necrosis 100\%); partial response: PR (decrease in the sum of diameters $30 \%$ ); stable disease: SD (no partial response or no progressive disease); or progressive disease: PD $(20 \%$ increase in the sum of the diameters) [10].

Routine follow-up consisted of clinical and radiological examination every 6 months after transplantation.

Outcome parameters were percentage of patients reaching transplantation, downstaging, tumor necrosis rate, overall survival after listing, and overall survival after liver transplantation.

\section{Statistical analysis}

Continuous data are given as median and interquartile range (IQR; range from the $25^{\text {th }}$ to the $75^{\text {th }}$ percentile), or mean and standard deviation, where appropriate. Discrete data are presented as counts and percentages. Chi-square tests or, if appropriate, exact tests were used to compare groups of categorical data. For comparisons of continuous data a MannWhitney $U$ test was performed. Kaplan-Meier survival estimates were used to calculate graft and patient survival, and the Mantel-Cox log-rank test was used to compare survival between groups. A two-sided $p$ value of $<0.05$ was considered statistically significant. All calculations were performed using SPSS for Mac 19 (IBM SPSS Statistics for Macintosh, Version 19, Armonk, NW: IBM Corp.).

The study was approved by the Medical University of Vienna Ethics Board (Research ethics reference number 0994/2010).

\section{Results}

We identified 150 patients with hepatocellular carcinoma matching the primary study criteria. A total of 4 patients had to be excluded from analysis for removal from the waiting list for non-HCC-related reasons, leaving a total of 146 patients for final analysis. The patient selection flowchart is depicted in Fig. 1.

The mean age was $56.9( \pm 7.6)$ years. $132(86 \%)$ patients were male, 20 (14\%) were female. 63 (43\%) patients had hepatitis C, 43 (29\%) had alcoholic cirrhosis, $11(8 \%)$ had hepatitis $B$, and $30(20 \%)$ patients hat combined or other etiologies of liver cirrhosis. Baseline demographic data are provided in Table 1.

$63 \%$ (92 patients) of this cohort underwent OLT, $21 \%$ (30 patients) were removed due to tumor progression, 9\% (13 patients) died while waiting for transplant. The mean time on the waiting list was $8.2( \pm 5.5)$ months. Mean tumor size was $2.5( \pm 1.1) \mathrm{cm}$, mean number of nodules was $2.3( \pm 1.9)$.

At time of listing, $70 \%$ (102 patients) were within Milan criteria (MC_IN), whereas 30\% (44 patients) were beyond Milan criteria (MC_OUT).

\section{Locoregional therapy (LRT)}

In this cohort, $55 \%$ (81 patients) received TACE-based locoregional therapy, 27\% (39 patients) a PEI/RFA regimen, and $18 \%$ (26 patients) had no treatment while on the waiting list. Detailed information is provided in Fig. 1.

Overall, a mean of $1.8( \pm 1.6)$ sessions were performed. Treatments performed were not significantly different between groups.

\section{Multimodality locoregional therapy}

In 29 patients a combined-multimodality-LRT (mmLRT) was performed: TACE and PEI in 14 (48\%), TACE and RFA in 11 (38\%), and PEI and RFA in 2 (7\%), and TACE/PEI/RFA in 2 (7\%).

There was a trend towards longer waiting time in patients receiving mmLRT (10.2 vs. 8 months, $p=$ 0.07 ). Lesion size or numbers were not significantly 
Fig. 1 Study selection flowchart of HCC patients receiving liver transplantation. $H C C$ hepatocellular carcinoma, TACE transarterial chemoembolization, $R F A$ radiofrequency ablation, $P E /$ percutaneous ethanol injection, $T X$ transplanted, $D O L$ died on list, TP removed for tumor progression, OR removed for other reasons, FU follow-up

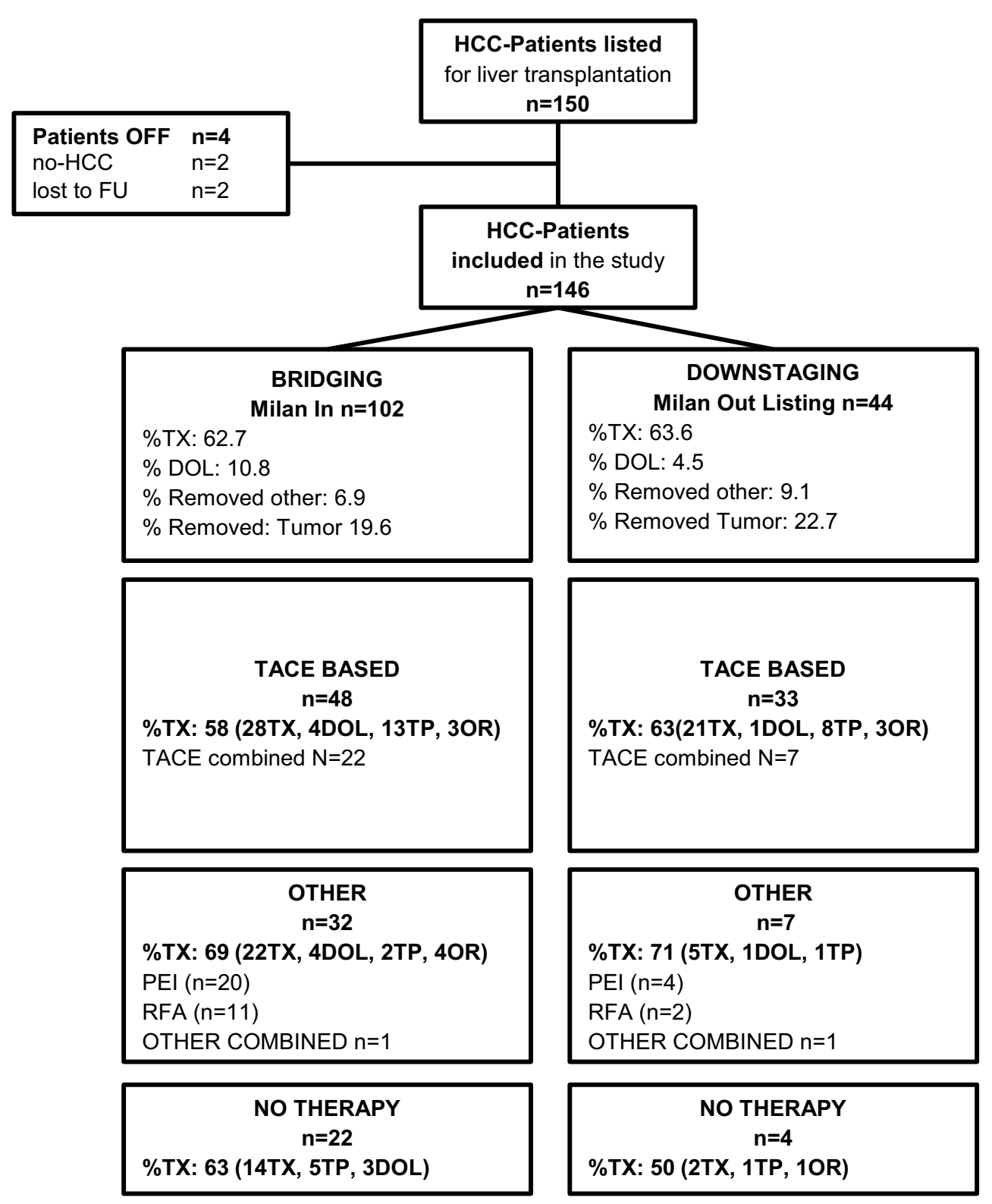

HCC - hepatocellular carcinoma, TACE - trans arterial chemo embolization, RFA - radio frequency ablation, PEI - percutaneous ethanol injection, TX -Transplanted, DOL - died on list, TP - removed for tumor progression, OR - removed for other reasons different between groups. Detailed information on LRT is shown in Fig. 1.

\section{Endpoint transplantation}

Overall, 92 patients (63\%) were transplanted. Transplant rates were not different for patients within and beyond Milan criteria, $63 \%$ vs. $63 \%$ respectively. TACE- and RFA/PEI-based LRT also showed equal transplant rates; detailed data is provided in Fig. 1.

\section{Response according to LRT}

Using mRECIST, overall, 25 (27.2\%) patients showed a complete response (CR), 29 (31.5\%) patients showed a partial response (PR), 26 patients $(28.3 \%)$ had stable disease (SD), and 12 patients (13.0\%) had progressive disease (PD) to/during LRT.

Patients receiving TACE had the highest CR rate (41.2\% vs. PEI $30.0 \%$, RFA 33.3\%). Patients receiving combined treatments mmLRT showed the lowest rate of $\mathrm{CR}(12.5 \%)$.

Furthermore, patients receiving RFA also showed the highest necrosis rate. $(84.9 \%$ vs. TACE $72.0 \%$ and 
Table 1 Patient characteristics and overall survival data for all patients listed for liver transplantation $(N=146)$

\begin{tabular}{|c|c|c|c|c|c|c|c|c|c|}
\hline & \multirow[t]{2}{*}{$\begin{array}{l}\text { All patients } \\
N=146\end{array}$} & \multicolumn{3}{|c|}{$\begin{array}{l}\text { Milan in listing } \\
N=102\end{array}$} & \multirow[t]{2}{*}{$p$-value } & \multicolumn{3}{|c|}{$\begin{array}{l}\text { Milan out listing } \\
N=44\end{array}$} & \multirow[t]{2}{*}{$p$-value } \\
\hline & & $\begin{array}{l}\text { TACE }+ \\
N=48\end{array}$ & $\begin{array}{l}\mathrm{PEI} / \mathrm{RFA} \\
N=32\end{array}$ & $\begin{array}{l}\mathrm{NO} \\
N=22\end{array}$ & & $\begin{array}{l}\text { TACE }+ \\
N=33\end{array}$ & $\begin{array}{l}\text { PEI/RFA } \\
\mathrm{N}=7\end{array}$ & $\begin{array}{l}\text { NO } \\
N=4\end{array}$ & \\
\hline Mean age (years) & $56.9 \pm 7.6$ & $56.9 \pm 8.2$ & $56.2 \pm 7.5$ & $55.2 \pm 7.3$ & 0.72 & $59.1 \pm 5.9$ & $58.0 \pm 6.7$ & $52.3 \pm 5.0$ & 0.11 \\
\hline Sex (\% female) & 14 & 17 & 12 & 23 & 0.62 & 9 & 14 & 0 & 0.75 \\
\hline Mean nr. treatments & $1.8 \pm 1.6$ & $2.6 \pm 1.7$ & $1.9 \pm 1.3$ & - & 0.012 & $2.2 \pm 1.6$ & $1.7 \pm 1.1$ & - & 0.44 \\
\hline Mean WT (months) & $8.2 \pm 5.5$ & $9.1 \pm 5.7$ & $8.9 \pm 5.0$ & $7.0 \pm 5.8$ & 0.32 & $7.8 \pm 5.9$ & $5.3 \pm 2.5$ & $5.3 \pm 4.5$ & 0.42 \\
\hline$\%$ transplanted & 63 & 58 & 69 & 64 & 0.65 & 64 & 71 & 50 & 0.79 \\
\hline Cirrhosis etiology & - & - & - & - & 0.049 & - & - & - & 0.62 \\
\hline PHCC & 62 & 13 & 18 & 10 & - & 15 & 3 & 3 & - \\
\hline $\mathrm{ALCl}$ & 43 & 16 & 9 & 9 & - & 8 & 1 & 0 & - \\
\hline PHBC & 11 & 6 & 0 & 0 & - & 4 & 1 & 0 & - \\
\hline Other & 16 & 7 & 2 & 1 & - & 6 & 0 & 0 & - \\
\hline Combined & 14 & 6 & 3 & 2 & - & 0 & 2 & 1 & - \\
\hline Mean nr. of nodules & $2.3 \pm 1.9$ & $1.5 \pm 0.8$ & $1.4 \pm 0.8$ & $1.5 \pm 0.70$ & 0.34 & $3.9 \pm 2.0$ & $5.1 \pm 2.2$ & $6.3 \pm 2.4$ & 0.066 \\
\hline Mean size of nodules & $2.5 \pm 1.0$ & $2.6 \pm 1.2$ & $2.5 \pm 0.9$ & $2.2 \pm 1.1$ & 0.14 & $2.2 \pm 1.0$ & $2.2 \pm 0.8$ & $1.6 \pm 0.6$ & 0.48 \\
\hline Survival listing \% & - & - & - & - & 0.37 & - & - & - & 0.50 \\
\hline 1 year & $80 \%$ & $80 \%$ & $80 \%$ & $78 \%$ & - & $80 \%$ & $72 \%$ & $100 \%$ & - \\
\hline 3 year & $59 \%$ & $41 \%$ & $66 \%$ & $60 \%$ & - & $50 \%$ & $58 \%$ & $75 \%$ & - \\
\hline 5 year & $50 \%$ & $41 \%$ & $60 \%$ & $48 \%$ & - & $50 \%$ & $30 \%$ & $38 \%$ & - \\
\hline MOS & $33.4 \pm 26.9$ & $\begin{array}{l}29.1 \pm \\
21.9\end{array}$ & $34.7 \pm 30.4$ & $\begin{array}{l}44.1 \pm \\
31.1\end{array}$ & - & $\begin{array}{l}32.3 \pm \\
24.8\end{array}$ & $33.1 \pm 38.8$ & $\begin{array}{l}49.6 \pm \\
15.6\end{array}$ & - \\
\hline
\end{tabular}

ALCl alcoholic cirrhosis, NO no treatment, $P E /$ percutaneous ethanol instillation, $P H C C$ post hepatitis $C$ cirrhosis, $P H B C$ post hpeatits B cirrhosis, RFA radiofrequency ablation, TACE transarterial chemoembolisation, WT waiting time

PEI 64.9\%). Patients receiving mmLRT showed the lowest necrosis rate $56.4 \%(p=0.15)$.

\section{Downstaging}

At the time of listing, 44 patients were beyond Milan criteria (MC_OUT). Eleven patients (25\%) who were MC_OUT at time of listing were not transplanted.

Nineteen patients were successfully downstaged to MC_IN: TACE was used in 13 patients (46.4\%), PEI in 3 patients $(10.7 \%)$, RFA in 1 pt $(3.6 \%)$, and 2 patients (7.1\%) received mmLRT. Downstaging was verified in explanted liver specimens. Detailed information is seen in Table 2.

\section{Severe adverse events}

In this cohort, a total of 12 severe adverse events (SAE) were recorded, 6 patients died, 2 patients were delisted. 4 patients were transplanted.

Detailed information is provided in Table 3. No significant difference between TACE and other LRTs was seen.

\section{Survival}

\section{Intention-to-treat survival analysis}

One-, 3-, and 5-year ITT waiting list survival was $80 \%$, $59 \%$, and $50 \%$ respectively (Fig. 2a). No difference was seen in ITT survival for patients within or beyond Milan criteria (Fig. 2b).

Overall survival from listing was comparable between LRT treatment groups (Table 1).

\section{Post-transplant survival}

Overall 1-, 3-, and 5-year post-transplant survival of 92 transplanted patients was $82 \%, 78 \%$, and $76 \%$ respectively (Fig. 3a).

One-, 3-, and 5-year overall survival were comparable for downstaged and non-downstaged patients at $85 \%$ vs. $94 \%$, $74 \%$ vs. $72 \%$, and $67 \%$ vs. $68 \%$ respectively $(p=0.67)$.

Patients who received multimodal LRT (mmLRT) showed a lower 1-, 3-, and 5-year post-transplant survival when compared with patients who received any single LRT $(68 \%, 58 \%$, and $58 \%$ versus $82 \%, 75 \%$, and $70 \% ; p=0.05$; Fig. 3b).

\section{Discussion}

This study evaluates different locoregional treatment strategies for hepatocellular carcinoma patients listed for transplantation. We found that patients who are in need of multiple types of treatment showed somewhat lower overall survival after transplantation.

A variety of publications exist on locoregional therapies for HCC before transplantation. Even though there is a lack of prospective RCTs, there is consensus that patients with HCC and an expected waiting 
Table 2 Tumor characteristics, mRECIST, and survival in patients after liver transplantation $(N=92)$

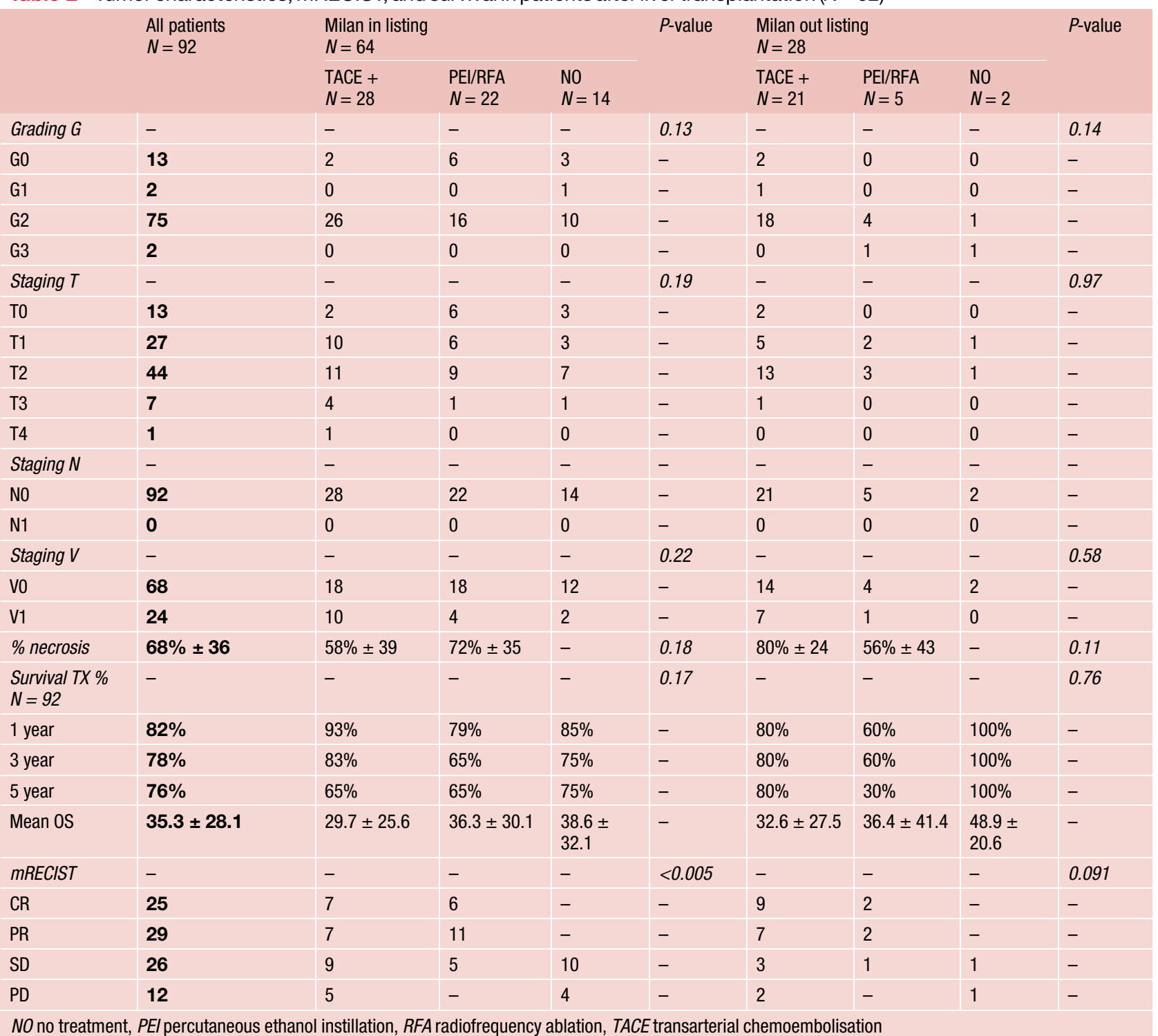

Table 3 Severe adverse events 4 weeks after LRT

\begin{tabular}{|l|l|l|}
\hline Portal vein thrombosis & TACE & Died on list \\
\hline Portal vein thrombosis & TACE & Died on list \\
\hline Portal vein thrombosis & TACE & Transplanted \\
\hline Portal vein thrombosis & TACE & Transplanted \\
\hline Portal vein thrombosis & PEI & Transplanted \\
\hline Ascites & RFA & OFF list \\
\hline Insult & RFA & OFF list \\
\hline Caput pancreas necrosis & TACE & Transplanted \\
\hline Caput pancreas necrosis & TACE & Died on list \\
\hline Other & TACE & Died on list \\
\hline Other & PEI & Died on list \\
\hline Other & TACE & Transplanted \\
\hline PEI & & Terctallon \\
\hline
\end{tabular}

PEI percutaneous ethanol instillation, RFA radiofrequency ablation, TACE transarterial chemoembolisation time of longer than 6 months should undergo locoregional therapy for HCC [14]. To this day, no single strategy has proved to be superior in terms of tumor response, dropout from the waiting list, and outcome after transplantation [15]. TACE has reported tumor response rates up to almost $60 \%$ [16-21], and RFA is reported to be somewhat higher [22-24]. Our data are in concordance with these previous findings, showing a mean necrosis rate of $58 \%$ for TACE and $72 \%$ for RFA, not reaching significant difference. Data on waiting list dropouts are limited in previous reports, especially for cohorts with RFA [15]. Dropout rates vary highly in reports between 3 and 35\%, for TACE and up to $25 \%$ for RFA [17, 19, 22, 23, 25, 26]. These reports should be interpreted with caution, as waiting times differ significantly and some are pre-MELD era publications. This cohort of patients who underwent bridging or downstaging have comparable transplant rates. In addition, direct comparison between differ- 

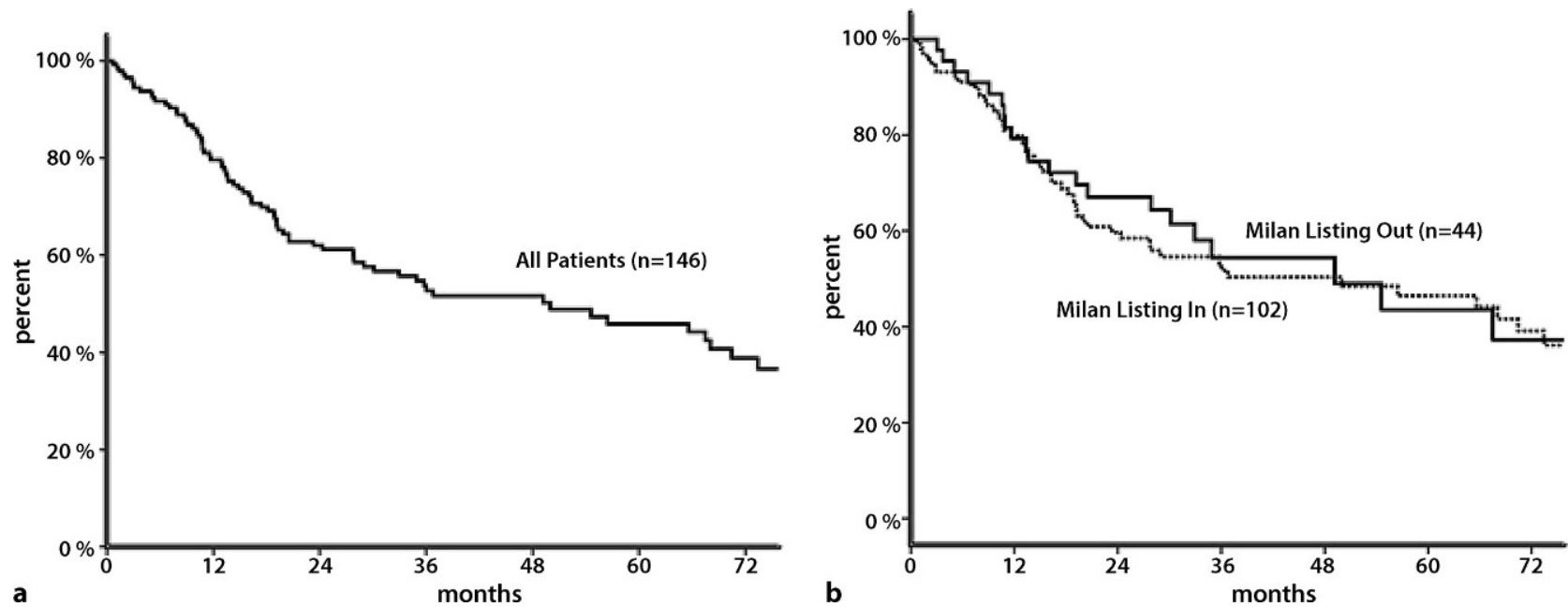

Fig. 2 a Kaplan-Meier survival: intention-to-treat survival from listing $(N=146)$. b Kaplan-Meier survival: intention-to-treat survival from listing according to Milan criteria $(N=146)$
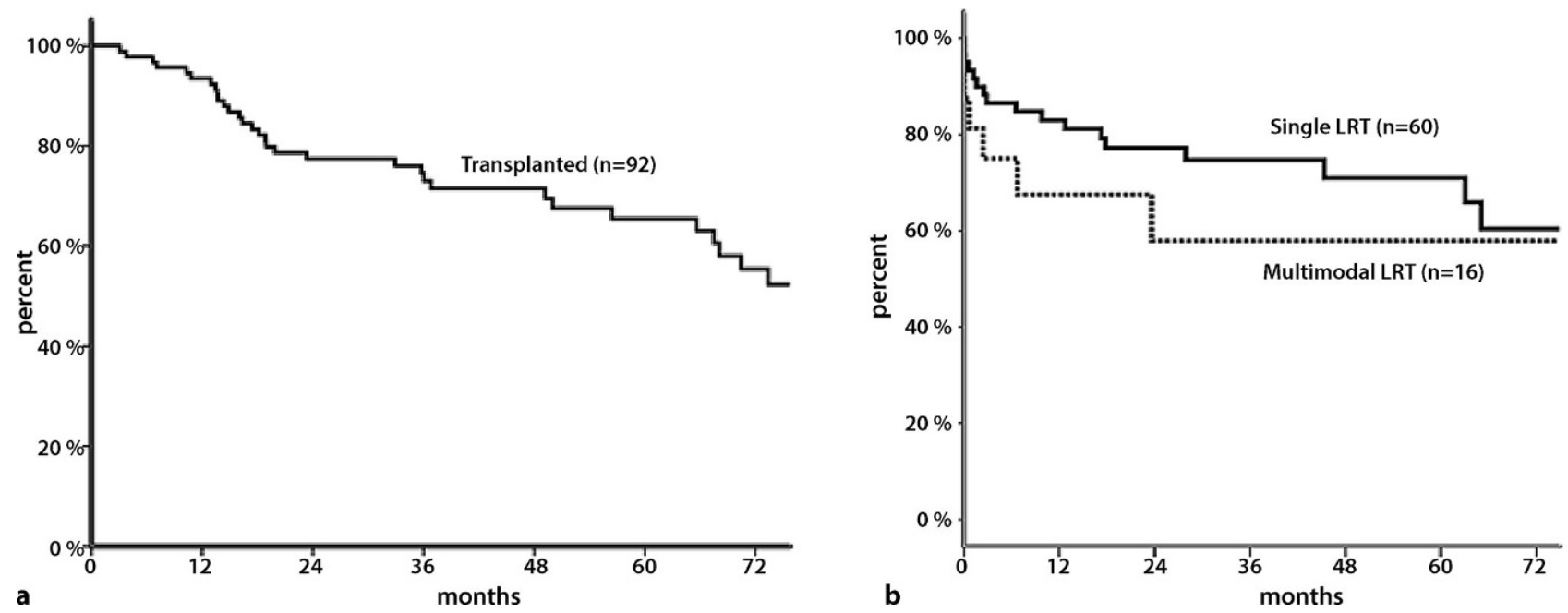

Fig. 3 a Kaplan-Meier survival: overall post-transplant survival $(N=92)$. b Kaplan-Meier survival: overall post-transplant survival according to single or multimodality locoregional treatment $(\mathrm{LRT})(N=76)$

ent LRT strategies showed no significant difference in dropout rates between groups. It is noteworthy that severe adverse events were evenly distributed and did not negatively impact the transplantation rate.

Previous studies report the 5-year overall posttransplant survival for HCC to be around $65 \%[15$, 18]. Patients with tumors that have complete necrosis after TACE might have beneficial outcome [19]; a clear survival benefit for patients with any LRT has not been proven so far $[15,27,28]$. We found equal intention-to-treat and post-transplant survival rates for all patients in this cohort. Patients receiving more than one type of bridging therapy, however, showed a somewhat lower post-transplant survival. Tumor size was not different between groups. Thus this fact might be indicative of poorer tumor biology. Data on multimodality treatment for HCC in the transplant setting are limited to the setting of unresectable HCC larger than $3 \mathrm{~cm}[29,30]$. Only one study eval- uating multimodality treatment in 44 patients with early stage HCC was identified, reporting $76 \%$ mean necrosis and a low transplant rate of $44 \%$ [31].

We are aware that this study has some limitations. First of all, it is retrospective in design. In addition, despite the large cohort size, the treatment groups are unevenly distributed, with patients receiving TACE being the largest group. However, no significant differences in tumor-related baseline parameters (size of nodules, number of nodules) or baseline demographic data were seen between groups.

In conclusion, our data show that patients with or without locoregional therapies have comparable longterm survival when transplanted. TACE and ablative strategies such as RFA are equally effective in bridging to transplantation and downstaging. Patients in need of more than one treatment modality might identify a cohort with inferior post-transplant survival. 
Acknowledgements Open access funding provided by Medical University of Vienna.

Conflict of interest G.P. Györi, D.M. Felsenreich, G.R. Silberhumer, T. Soliman, and G.A. Berlakovich declare that they have no competing interests.

Open Access This article is distributed under the terms of the Creative Commons Attribution 4.0 International License (http://creativecommons.org/licenses/by/4.0/), which permits unrestricted use, distribution, and reproduction in any medium, provided you give appropriate credit to the original author(s) and the source, provide a link to the Creative Commons license, and indicate if changes were made.

\section{References}

1. Zheng Z, Liang W, Milgrom DP, Schroder PM, Kong NS, Yang $\mathrm{C}$, et al. Liver transplantation versus liver resection in the treatment of hepatocellular carcinoma: a aeta-analysis of observational studies. Transplantation. 2013; doi:10.1097/ tp.0b013e3182a89383.

2. Mazzaferro V, Bhoori S, Sposito C, Bongini M, Langer M, Miceli R, et al. Milan criteria in liver transplantation for hepatocellular carcinoma: an evidence-based analysis of 15 years of experience. Liver Transplant. 2011;17(Suppl 2):S44-S57.

3. Mazzaferro V. Results of liver transplantation: with or without Milan criteria? Liver Transplant. 2007;13(11 Suppl 2):S44-S7.

4. Unek T, Karademir S, Arslan NC, Egeli T, Atasoy G, Sagol $\mathrm{O}$, et al. Comparison of Milan and UCSF criteria for liver transplantation to treat hepatocellular carcinoma. World J Gastroenterol. 2011;17(37):4206-12.

5. Mazzaferro V, Llovet JM, Miceli R, Bhoori S, Schiavo M, Mariani L, et al. Predicting survival after liver transplantation in patients with hepatocellular carcinoma beyond the Milan criteria: a retrospective, exploratory analysis. Lancet Oncol. 2009;10(1):35-43.

6. Ruiz Gomez A, Couce ML, Garcia-Villoria J, Torres A, Bana Souto A, Yague J, et al. Clinical, genetic, and therapeutic diversity in 2 patients with severe mevalonate kinase deficiency. Pediatrics. 2012;129(2):e535-e9.

7. Northup PG, Berg CL. Hepatocellular carcinoma and model for end-stage liver disease exceptions: the more we understand, the more challenging the allocation gets. Liver Transplant. 2012;18(4):381-3.

8. Si Y, Hu X, Du H, Lou W, Zhang H, Cao F, et al. Transarterial chemoembolization for patients with unresectable hepatocellular carcinoma: a retrospective study of a 5-year experience in a single institution. Hepatogastroenterology. 2013;60(126):1405-8.

9. Wong LL, Tanaka K, Lau L, Komura S. Pre-transplant treatment of hepatocellular carcinoma: assessment of tumor necrosis in explanted livers. Clin Transplant. 2004;18(3):227-34.

10. Meza-Junco J, Montano-Loza AJ, Liu DM, Sawyer MB, Bain VG, Ma M, et al. Locoregional radiological treatment for hepatocellular carcinoma; Which, when and how? Cancer Treat Rev. 2012;38(1):54-62.

11. Yao FY, Kerlan RK Jr., Hirose R, Davern TJ 3rd, Bass NM, Feng S, et al. Excellent outcome following down-staging of hepatocellular carcinoma prior to liver transplantation: an intention-to-treatanalysis. Hepatology. 2008;48(3):819-27.

12. De Luna W, Sze DY, Ahmed A, Ha BY, Ayoub W, Keeffe EB, et al. Transarterial chemoinfusion for hepatocellular carcinoma as downstaging therapyand abridge towardliver transplantation. Am J Transplant. 2009;9(5):1158-68.

13. Chapman WC, Majella Doyle MB, StuartJE, Vachharajani N, Crippin JS, Anderson CD, et al. Outcomes of neoadjuvant transarterial chemoembolization to downstage hepatocellular carcinoma before liver transplantation. Ann Surg. 2008;248(4):617-25.

14. Clavien PA, Lesurtel M, Bossuyt PM, Gores GJ, Langer B, Perrier A, et al. Recommendations for liver transplantation for hepatocellular carcinoma: an international consensus conference report. Lancet Oncol. 2012;13(1):e11-e22.

15. Pompili M, Francica G, Ponziani FR, Iezzi R, Avolio AW. Bridging and downstaging treatments for hepatocellular carcinoma in patients on the waiting list for liver transplantation. World J Gastroenterol. 2013;19(43):7515-30.

16. GraziadeiIW,Sandmueller H, WaldenbergerP, Koenigsrainer A, Nachbaur K, Jaschke W, et al. Chemoembolization followed by liver transplantation for hepatocellular carcinoma impedes tumor progression while on the waiting list and leads to excellent outcome. Liver Transplant. 2003;9(6):557-63.

17. HayashiPH, Ludkowski M, Forman LM, Osgood M, Johnson S, Kugelmas M, et al. Hepatic artery chemoembolization for hepatocellular carcinoma in patients listed for liver transplantation. Am J Transplant. 2004;4(5):782-7.

18. Decaens T, Roudot-Thoraval F, Bresson-Hadni S, Meyer C, Gugenheim J, Durand F, et al. Impact of pretransplantation transarterial chemoembolization on survival and recurrence after liver transplantation for hepatocellular carcinoma. Liver Transplant. 2005;11(7):767-75.

19. Millonig G, Graziadei IW, Freund MC, Jaschke W, Stadlmann S, Ladurner R, et al. Response to preoperative chemoembolization correlates with outcome after liver transplantation in patients with hepatocellular carcinoma. Liver Transplant. 2007;13(2):272-9.

20. Tsochatzis E, Garcovich M, Marelli L, Papastergiou V, Fatourou E, Rodriguez-Peralvarez ML, et al. Transarterial embolization as neo-adjuvant therapy pretransplantation in patients with hepatocellular carcinoma. Liver Int. 2013;33(6):944-9.

21. Golfieri R, Cappelli A, Cucchetti A, Piscaglia F, Carpenzano M, Peri E, et al. Efficacy of selective transarterial chemoembolization in inducing tumor necrosis in small $(\langle 5 \mathrm{~cm})$ hepatocellular carcinomas. Hepatology. 2011;53(5):1580-9.

22. Mazzaferro V, Battiston C, Perrone S, Pulvirenti A, Regalia E, Romito R, et al. Radiofrequency ablation of small hepatocellular carcinoma in cirrhotic patients awaiting liver transplantation: a prospective study. Ann Surg. 2004;240(5):900-9.

23. LuDS, Yu NC, Raman SS, LassmanC, Tong MJ, Britten C, etal. Percutaneous radiofrequency ablation of hepatocellular carcinoma as a bridge to liver transplantation. Hepatology. 2005;41(5):1130-7.

24. Pompili M, MiranteVG, Rondinara G, Fassati LR, Piscaglia F, AgnesS, etal. Percutaneous ablation proceduresin cirrhotic patients with hepatocellular carcinoma submitted to liver transplantation: assessment of efficacy at explant analysis and of safety for tumor recurrence. Liver Transplant. 2005;11(9):1117-26.

25. Majno P, Giostra E, Mentha G. Management of hepatocellular carcinoma on the waiting list before liver transplantation: time for controlled trials? Liver Transplant. 2007;13(11 Suppl2):S27-S35.

26. Fontana RJ, Hamidullah H, Nghiem H, Greenson JK, Hussain $\mathrm{H}$, Marrero J, et al. Percutaneous radiofrequency thermal ablation of hepatocellular carcinoma: a safe and 
effective bridge to liver transplantation. Liver Transplant. 2002;8(12):1165-74.

27. Porrett PM, Peterman H, Rosen M, Sonnad S, Soulen M, Markmann JF, et al. Lack of benefit of pre-transplant locoregional hepatic therapy for hepatocellular cancer in the current MELD era. Liver Transplant. 2006;12(4):665-73.

28. Heckman JT, Devera MB, Marsh JW, Fontes P, Amesur NB, Holloway SE, et al. Bridging locoregional therapy for hepatocellular carcinoma prior to liver transplantation. Ann Surg Oncol. 2008;15(11):3169-77.

29. Rossi S, Garbagnati F, Lencioni R, Allgaier HP, Marchiano A, FornariF, etal. Percutaneousradio-frequency thermalabla- tion of nonresectablehepatocellular carcinoma after occlusion of tumor blood supply. Radiology. 2000;217(1):119-26.

30. VeltriA, Moretto P,DoriguzziA, Pagano E, Carrara G, Gandini G. Radiofrequency thermal ablation (RFA) after transarterial chemoembolization (TACE) as a combined therapy for unresectable non-early hepatocellular carcinoma (HCC). Eur Radiol. 2006;16(3):661-9.

31. Ashoori N, Bamberg F, Paprottka P, Rentsch M, Kolligs FT, Siegert S, et al. Multimodality treatment for early-stage hepatocellular carcinoma: a bridging therapy for liver transplantation. Digestion. 2012;86(4):338-48. 